\title{
Overview of HF10 spinal cord stimulation for the treatment of chronic pain and an introduction to the Senza Omnia ${ }^{T M}$ system
}
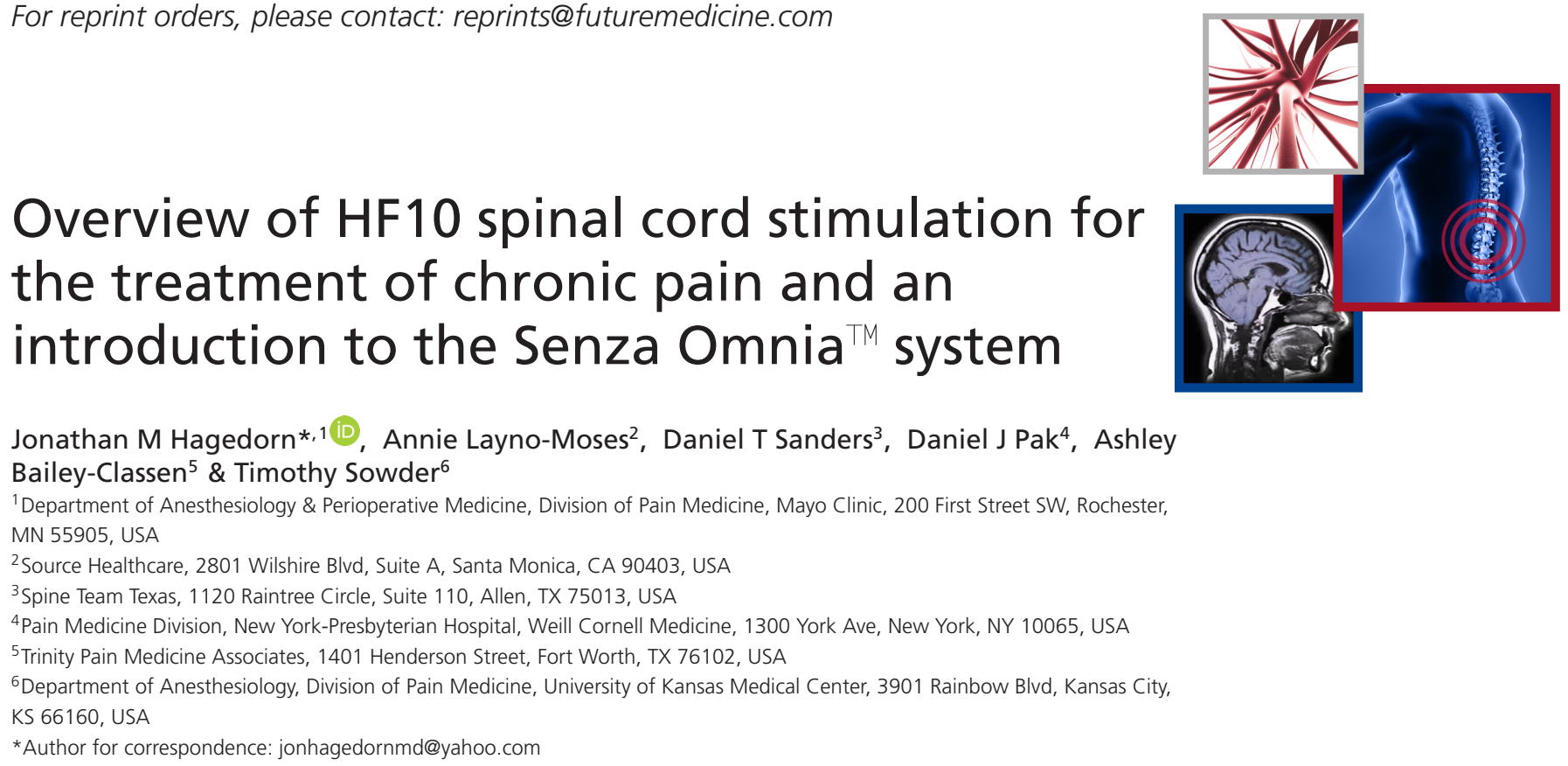

\section{Practice points}

- Spinal cord stimulation (SCS) is a well-studied and increasingly used treatment modality for chronic intractable pain states.

- The Senza SCS systems deliver high-frequency stimulation, which has proven superiority over traditional SCS systems for the treatment of back and leg pain.

- The Omnia ${ }^{T M}$ implantable pulse generator is the newest offering in the Senza line and has the ability to provide high-frequency stimulation in addition to multiple other waveforms.

Chronic intractable pain affects a significant percentage of the worldwide population, and it is one of the most disabling and expensive health conditions across the globe. Spinal cord stimulation (SCS) has been used to treat chronic pain for a number of years, but high-frequency SCS was not the US FDA approved until 2015. In this review, we describe the history and development of high-frequency SCS and discuss the benefits of the Omnia ${ }^{T M}$ implantable pulse generator. We also provide a thorough literature review of the published work, highlighting the efficacy and safety profiles of high-frequency SCS for the treatment of multiple chronic pain conditions. Lastly, we offer our outlook on future developments with the Omnia SCS system.

First draft submitted: 22 June 2020; Accepted for publication: 29 July 2020; Published online: 18 August 2020

Keywords: chronic pain • neurostimulation • spinal cord stimulation

The use of spinal cord stimulation (SCS) for the treatment of chronic pain was introduced over 50 years ago [1]. Since its inception, the technology has evolved dramatically, and this is particularly evident over the past decade. Recent years have seen the creation of new waveforms and variations in electrical dosing, but arguably the most important advancement has been the introduction of high-frequency, $10 \mathrm{kHz}$ SCS (HF10). While traditional SCS (T-SCS) relies on generation of a paresthesia at the site of pain, HF10 is entirely paresthesia-free. This novel device has been shown to provide superior pain relief and outstanding patient-reported outcomes. This article provides an overview of HF10 and highlights Nevro's new Omnia ${ }^{\top M}$ implantable pulse generator (IPG) (Nevro Corp., CA, USA).

Nevro was founded in 2006 and introduced $10 \mathrm{kHz}$ SCS with the goal of offering an effective therapy for low-back pain and other chronic pain syndromes. HF10 therapy was approved for use in Europe in 2010, Australia in 2011 and the USA in 2015. The therapy is backed by robust clinical evidence demonstrating improved and sustained pain relief versus T-SCS through rigorous level I evidence: SENZA-RCT published at 12 and 24 months [2,3]. 
At 24 months, the responder rate was $76 \%$ with a $2.4-\mathrm{cm}$ visual analog scale (VAS) for both back and leg pain. Outcomes were further validated in a 1660-patient real-world outcomes publication in which patients reported at $74 \%$ responder rate [4]. In addition HF10 patients achieved a $68 \%$ reduction in opioid usage [5].

HF10 is a paresthesia-free therapy, which allows for numerous physician and patient benefits. For physicians, no paresthesia mapping is required during placement as leads are placed anatomically. This results in a predictable and repeatable procedure in which the patient does not need to be awakened from sedation to provide paresthesia coverage feedback. Patient benefits include the absence of paresthesias at rest, which can be perceived as uncomfortable, and the lack of supratherapeutic stimulation that can often accompany positional changes with T-SCS. Additionally, paresthesia-free stimulation allows for usage while driving as well as enabling sleep without restrictions. In fact, 99\% of patients report that they sleep with their device on [4].

The first widely available SCS systems from Nevro, Senza I and Senza II, were designed specifically to deliver HF10 therapy [6]. The introduction of the Omnia system allows greater programming diversity and therapeutic versatility by introducing the availability of multiple stimulation settings within a single battery.

\section{SCS overview}

\section{Mechanism of action}

There are various theories regarding the mechanism of action of how SCS provides pain relief [7]. One of the earliest theories is Melzack and Wall's gate control theory of pain, first proposed in 1965 [8]. This theory suggests that stimulating afferent low-threshold A $\beta$-fibers results in inhibition of spinal nociceptive transmission [9]. Wall and Melzack's work helped set the foundation for neuromodulation research and led to pain therapies such as SCS and transcutaneous electrical nerve stimulation $[7,9]$. The gate control theory has evolved into the concept of a 'neuromatrix' that involves multiple interacting neuronal pathways. In T-SCS, electrodes are placed over the dorsal columns (DCs) to deliver electrical pulses at a frequency of 30-60 Hz, which elicit paresthesias at the site of pain. Activating the DCs is thought to inhibit pain signal transmission [9].

T-SCS is associated with inhibiting neuronal activity in the dorsal horn via activation of spinal inhibitory interneurons through activity in A $\beta$-fibers [10-14]. T-SCS has been found to decrease wide dynamic range (WDR) neuronal activity in rat studies; this may play a mechanistic role in T-SCS [14-16]. Furthermore, windup is blocked by T-SCS and stabilizes long-term potentiation that occurs in WDR neurons [11,17-19]. Other potential mechanisms may involve activating descending pain-inhibitory pathways, inducing inhibitory postsynaptic potentials in dorsal horn neurons, and inhibiting presynaptic afferent inputs [20,21].

Additional studies suggest $A \beta$-fiber input activates a subset of GABAergic interneurons [22,23]. Traditional SCS stimulates the anterior pretectal nucleus activating descending pain inhibitory pathways [24]. Activation of supraspinal circuitry may contribute up to $50 \%$ of pain inhibitory effects from T-SCS [25,26]. Additionally, rat studies showed SCS-activated serotonergic cells and OFF cells in the rostral ventromedial medulla [27]. The SCSresponsive rats were found to have an increase in 5-hydroxytyptamine in the lumbar dorsal horn after SCS. SCS has been shown to increase extracellular GABA in the spinal cord and is linked to a reduction in glutamate and aspartate that lasts longer than the stimulation period [28-30].

SCS generates serotonin release into the spinal cord; this decreases neuronal excitability and pain transmission [31,32]. Serotonin may increase spinal production of dynorphin, enkephalin and GABA [33]. Moreover, SCS generates acetylcholine, adenosine and noradrenaline release [34-36]. Additionally, SCS may stimulate transcriptional and post-translational changes in neurons [9].

The exact mechanism of HF10 remains uncertain. Studies have suggested that, contrary to conventional SCS, high-frequency SCS (frequencies $>5 \mathrm{kHz}$ ) may not involve the DCs [37]. Multiple studies have indicated that pain inhibition at varying kilohertz levels of frequency and $50-\mathrm{Hz}$ SCS appear to involve different neuronal mechanisms [38,39]. At frequencies above $5 \mathrm{kHz}$, inhibitory interneurons have been shown to be selectively activated [40]. Recently, Lee $e t$ al. confirmed similar results using a rodent model in which low-intensity HF10 selectively activated inhibitory interneurons in the spinal dorsal horn without activating DC fibers, thus providing paresthesia-free pain relief. A prior study suggested that HF10 stimulates the dorsal root or the dorsal root entry zone, which may suppress WDR neuronal hyperactivity [41]. Similarly, Arle et al. found that stimulation between 4.5 and $10 \mathrm{kHz}$ preferentially recruits small and medium fibers while blocking larger fibers, ultimately resulting in pain relief by inhibiting WDR cells [42]. Additionally, it appears that only with the use of $10 \mathrm{kHz}$ stimulation were pain neurons and the windup response inhibited [43]. 
Table 1. Omnia implantable pulse generator programming options.

\begin{tabular}{|ll}
\hline Stimulation setting & Definition \\
\hline High frequency (HF10) & Continuous stimulation; Frequency: 10,000 Hz, Pulse width: $30 \mu s$, Amplitude: $1-4 \mathrm{~mA}$ \\
\hline Low frequency (T-SCS) & Continuous stimulation; Frequency: 2-1200 Hz, Pulse width: $100-500 \mu \mathrm{s}$, Amplitude: $2-8 \mathrm{~mA}$ \\
\hline Pulse dosing & Noncontinuous stimulation; Intermittent HF10 stimulation (i.e., $25 \%$ on and $75 \%$ off); same settings as above \\
\hline Burst & $\begin{array}{l}\text { Noncontinuous stimulation; Five electrical impulses with an intraburst frequency of } 500 \mathrm{~Hz} \text {; Pulse width: } 1000 \mu \mathrm{s}, 2-8 \mathrm{~mA} \text {; Burst packets } \\
\text { repeated at frequency of } 40 \mathrm{~Hz}\end{array}$ \\
\hline Burst10k ${ }^{\mathrm{TM}}$ & Continuous stimulation; Burst stimulation with HF10 stimulation during interburst time periods; same settings as above \\
\hline Frequency pairing & Continuous stimulation; T-SCS stimulation with HF10 stimulation between electrical impulses; same settings as above \\
\hline
\end{tabular}

As a whole, the theories regarding mechanism of action for high-frequency SCS vary widely and further research is needed to provide a definitive answer.

\section{Implant procedure}

The patient is positioned prone and draped in the usual sterile fashion. Antibiotics are administered 30-60 min prior to skin incision. Using fluoroscopy, the appropriate vertebral level is confirmed for the placement of the leads [44]. The midline of the epidural space is targeted with interlaminar entry between T11-T12 and L2-L3 for lumbar implants. The skin entry point is typically the medial aspect of the pedicle below the intended interlaminar entry level. Skin is incised then dissection continues to the lumbar fascia with appropriate hemostasis.

Two introducer needles are inserted through ligamentum flavum into the epidural space and the leads are advanced to the midline of the desired vertebral level with fluoroscopic guidance. For back and leg pain, the most cephalad electrode of one lead is placed at the top of the T8 vertebra and the second lead has its most cephalad electrode at the top of the T9 vertebra. The most inferior electrode is usually situated at the bottom of the T11 vertebra. There should be overlapping of the leads at the T9-T10 disc space [44]. For neck and arm pain, the electrodes are usually placed over the $\mathrm{C} 2-\mathrm{C} 7$ vertebra for the cervical implant [45]. The leads are then anchored to the fascia and impedances are checked to ensure the integrity of the stimulation system [44,46].

The desired IPG implant site is identified with consideration of patient comfort and infection control. The pocket should not be larger than the IPG and no deeper than $2 \mathrm{~cm}$ from the surface of the skin. The IPG template can be used to estimate the size of the pocket [46]. Once the pocket is created, the leads are tunneled to the pocket and connected to the IPG. The IPG is inserted into the pocket; sutures may be used to secure the IPG to the patient's soft tissue. Communication between IPG and programmer are checked, and hemostasis and irrigation are performed. Wounds are closed and dressings applied in the usual surgical manner [46].

The use of anatomical-based surgical placement eliminates 'paresthesia mapping', the process that uses stimulation from the electrodes to ensure the patient's painful areas are covered with paresthesia. As such, the patient is able to remain sedated throughout the entire procedure [45].

\section{Introduction to Omnia}

\section{Evolution of Nevro offerings}

This review article highlights on the Omnia IPG. The Senza system was the initial IPG from Nevro Corporation and was the first to offer $10 \mathrm{kHz}$, paresthesia-independent stimulation for the treatment of chronic pain [47]. The US FDA approval of the device in 2015 came with superiority labeling to T-SCS following the Senza RCT [2]. It was the only SCS therapy indicated by the FDA to deliver pain relief without paresthesias or patient restrictions on motor vehicle operation while receiving therapy [6]. It was also the only implantable SCS system approved by the FDA with labeling for 3T conditional MRI compatibility for head and extremities. The second iteration of the Senza IPG, Senza II, was smaller with potential to improve patient comfort and reduce the incidence of IPG site pain, a well-described complication of implantable SCS therapies [48-50]. The Omnia IPG, the third and current offering from Nevro Corporation, was introduced in late 2019. It maintains the size of the Senza II with the ability to deliver a wider range of therapeutic stimulation programs.

\section{Omnia programming versatility}

Programming options available on the Omnia platform include HF10, low frequency, pulse dosing, burst, Burst $10 \mathrm{k}^{\mathrm{TM}}$ and frequency pairing (Table 1 ). 
Habituation or tolerance is the subsequent loss of therapeutic effect after initial success that cannot be explained by a hardware-related issue [49,50]. The rate of this phenomenon has been noted to be $13-25.9 \%$ and is a leading cause for device explant [48-50]. While poorly understood, contributing factors may be disease progression, plasticity of central pain pathways and fibrosis around the stimulating electrodes [49,50]. As reviewed by Reddy et al., there are some data to suggest that patients experiencing diminishing efficacy with their current SCS may benefit from conversion to an alternative treatment [51]. Additionally, early clinical experience demonstrates that for select difficult-to-treat pain populations, paired waveforms can provide additional opportunities for relief. In Russo et al.'s real-world results with Omnia from a retrospective audit of 493 patients across four Australian clinical sites, 26 patients with an average IPG duration of approximately 1.6 years were provided frequency pairing or Burst $10 \mathrm{k}^{\mathrm{TM}}$ to optimize their treatment as they were not reporting adequate relief and had exhausted current therapy options. The study demonstrated that compared with baseline, at the last follow-up $(72.9=/-12.6$ days $)$, patients treated with waveform pairing showed improvements in responder rates (from 17.4 to 60\%). Approximately $38 \%$ reported a decrease in their pain medication use since their previous follow-up visit [52].

The flexibility of Omnia to provide multiple alternative therapies improves the rate of durable response to SCS therapy and prevents device explant due to loss of efficacy. The pairing of waveforms across wide frequency ranges enables treatment that may utilize separate mechanisms of action. Lastly, the Omnia battery is designed with a lifespan exceeding 10 years regardless of the stimulation profile that is used, has conditional full-body MRI approval and is upgradeable to future waveforms and frequencies [6].

\section{Clinical efficacy}

The introduction of robust clinical data regarding the use of HF10 as a means of providing pain relief came by way of the SENZA series of clinical trials. The SENZA series of trials provided ample evidence that high-frequency DC SCS is safe and efficacious in the treatment of lower extremity radicular symptoms as well as axial low-back pain. There is a growing body of literature that demonstrates a broadening of the applications of HF10 including the treatment of chronic migraines, nonsurgical refractory back pain, axial neck pain and upper extremity radicular pain (Table 2). It is noteworthy that no prior clinical trials have been performed with a device that is capable of delivering energy multiple ways and this includes the Omnia IPG. Any potential benefits of enhanced programming capabilities remain to be proven.

In 2013, Van Buyten et al. published their work, which utilized high-frequency (up to $10 \mathrm{kHz}$ ) waveforms in the treatment of chronic, intractable pain of the back and/or limbs. A total of 83 patients were recruited and 82 patients took part in the study. Eighty eight percent (72 out of 82) of the patients had a successful trial period and $74 \%$ of patients who were implanted experienced at least $50 \%$ pain relief at the 6 -month follow-up. At 6 months, mean back pain VAS was reduced from 8.4 to $2.7(\mathrm{p}<0.001)$ and mean leg pain VAS was reduced from 5.4 to $1.4(\mathrm{p}<0.001)$. There were also improvements in the Oswestry disability index (ODI) and sleep [53]. Sustained relief was demonstrated in these patients at the 24-month follow-up with a mean back pain VAS score of $3.3 \pm 0.3$ from $8.4 \pm 0.1$ at baseline and a mean leg pain VAS score of $2.3 \pm 0.3$ from $5.4 \pm 0.4$. In all, for those implanted, $60 \%$ had $\geq 50 \%$ back pain relief and $71 \%$ had $\geq 50 \%$ leg pain relief after 24 months [5].

Kapural et al. published the SENZA-RCT randomized controlled trial across multiple US institutions in 2015. In their study, HF10 was compared with T-SCS (typically around $50 \mathrm{~Hz}$ ) in patients with both back and leg pain. A total of 198 patients were enrolled and 171 had a successful trial (86\%). At the 6-month follow-up visit, 76.4\% of patients received $\geq 50 \%$ back pain relief and $80.9 \%$ received this relief of their leg pain. This was in contrast to 51.9 and $54.4 \%$, respectively, for those in the T-SCS arm. This demonstrated the superiority of high-frequency stimulation for the treatment of low back and leg pain ( $p<0.001$ for both back and leg pain) [2]. The same sustained relief that was seen in the European study was also seen in the SENZA-RCT. At 24 months, $\geq 50 \%$ pain reduction of low-back pain was seen in $76.5 \%$ of high-frequency stimulation patients compared with $49.3 \%$ in the conventional arm $(\mathrm{p}<0.001)$. Likewise, this responder rate was $72.9 \%$ in the high-frequency arm versus $49.3 \%$ in the conventional arm for leg pain $(\mathrm{p}<0.001)$. Again, this showed the durable efficacy of this therapy that was superior to conventional means without increased incidence of adverse events (AEs) [3].

One year after SENZA-RCT was published, Arcioni et al. performed an open-label, exploratory study to assess the use of HF10 in the treatment of chronic, medically refractory migraines. Enrolled individuals underwent a 2-4 weeks tunneled cervical HF10 trial with subsequent implantation if they experienced a reduction in chronic migraine symptoms (pain intensity and/or migraine episodes) during the trial. Seventeen patients were trialed and 14 subjects remained implanted at 6 months (one trial failure, one trial infection, one implant site infection). At 6 


\section{Table 2. Studies evaluating high-frequency spinal cord stimulation.}

\begin{tabular}{|c|c|c|c|c|c|c|}
\hline Study (year) & Study type & Patients (n) & Condition investigated & Follow-up period & Results & Ref. \\
\hline $\begin{array}{l}\text { Van Buyten (2013); } \\
\text { Al-Kaisy (2014) }\end{array}$ & $\begin{array}{l}\text { Prospective, } \\
\text { multicenter }\end{array}$ & 83 & Low back and leg pain & 24 months & $\begin{array}{l}\text { - Back pain relief }>50 \% \text { in } 60 \% \text { of } \\
\text { patients with HF10 at } 24 \text { months } \\
\text { - Leg pain relief }>50 \% \text { in } 71 \% \text { of } \\
\text { patients with HF10 at } 24 \text { months }\end{array}$ & {$[5,53]$} \\
\hline Kapural $(2015,2016)$ & $\begin{array}{l}\text { Multicenter, } \\
\text { randomized, controlled }\end{array}$ & 198 & Low back and leg pain & 24 months & $\begin{array}{l}\text { - }>50 \% \text { back pain relief in } 77 \% \text { of } \\
\text { subjects with HF10 vs } 49 \% \text { with T-SCS at } \\
24 \text { months } \\
\text { - }>50 \% \text { leg pain relief in } 73 \% \text { of } \\
\text { subjects with HF10 vs } 49 \% \text { with T-SCS at } \\
24 \text { months }\end{array}$ & {$[2,3]$} \\
\hline Arcioni (2016) & $\begin{array}{l}\text { Prospective, } \\
\text { single-center }\end{array}$ & 17 & Chronic migraine & 6 months & $\begin{array}{l}\text { - }>30 \% \text { reduction in overall headache } \\
\text { days in } 50 \% \text { of patients at } 6 \text { months }\end{array}$ & [54] \\
\hline Al-Kaisy $(2017,2018)$ & $\begin{array}{l}\text { Prospective, } \\
\text { single-center }\end{array}$ & 20 & $\begin{array}{l}\text { low-back pain without } \\
\text { previous spine surgery }\end{array}$ & 36 months & $\begin{array}{l}\text { - Significant VAS reductions for axial } \\
\text { back (baseline VAS } 79 \pm 12 \text { to } \\
10 \pm 12 \mathrm{~mm} \text { ) and leg pain (VAS } 33 \pm 21 \\
\text { to } 9 \pm 13 \mathrm{~mm} \text { ) at } 36 \text { months } \\
\text { - Reductions in ODI (baseline } 53 \pm 13 \text { to } \\
19.8 \pm 13 \text { ) } \\
\text { - Decline in opioid use, } 88 \% \text { opioid-free } \\
\text { at } 36 \text { months }\end{array}$ & {$[55,56]$} \\
\hline Amirdelfan (2019) & $\begin{array}{l}\text { Prospective, } \\
\text { multicenter }\end{array}$ & 45 & Neck and arm pain & 12 months & $\begin{array}{l}\text { - Significant VAS reductions for neck } \\
\text { (baseline } 7.6 \pm 0.2 \text { to } 2.4+0.4 \mathrm{~cm} \text { ) and } \\
\text { arm pain }(7.1 \pm 0.3 \text { to } 1.8 \pm 0.5 \mathrm{~cm} \text { ) at } \\
3 \text { months } \\
\text { - Rate of neck and arm pain remitters } \\
\text { (VAS } \leq 2.5 \mathrm{~cm} \text { ) } 78.4 \text { and } 80 \% \text {, } \\
\text { respectively, at } 12 \text { months } \\
\text { - } 30 \% \text { decreased/eliminated opioid use } \\
\text { at } 12 \text { months }\end{array}$ & [57] \\
\hline Al-Kaisy (2019) & Post hoc analysis & 137 & Opioid usage & 12 months & $\begin{array}{l}\text { - } 41 \% \text { reduction in opioid use at } \\
12 \text { months (baseline } 104.2 \pm 9.0 \text { to } \\
61.4 \pm 6.9 \mathrm{MME}) \\
\text { - SENZA-EU with greater reduction } \\
(92.3 \pm 15.6 \text { to } 28.1 \pm 6.0 \mathrm{MME}) \\
\text { compared with SENZA-RCT } \\
(112.7 \pm 10.5 \text { to } 87.9 \pm 10.3 \mathrm{MME}) \\
\text { - High-dose subjects (>90 MME) prior to } \\
\text { HF10 with } 45.9 \% \text { reduction at } \\
12 \text { months ( } 196.8 \pm 14.2 \text { to } 106.5 \pm 14.1 \\
\text { MME) }\end{array}$ & [58] \\
\hline Thomson et al. (2018) & $\begin{array}{l}\text { Randomized, } \\
\text { controlled }\end{array}$ & 20 & Back and leg pain & 16 weeks & $\begin{array}{l}\text { - Mean back pain NRS scores decreased } \\
\text { from } 6.8 \pm 0.3 \text { (baseline, } \\
\text { mean } \pm \text { standard error of the mean) to } \\
3.2 \pm 0.3(1 \mathrm{kHz}), 3.5 \pm 0.3(4 \mathrm{kHz}) \text {, } \\
3.2 \pm 0.3(7 \mathrm{kHz}) \text { and } 3.3 \pm 0.4(10 \mathrm{kHz}) \text {. } \\
\text { These decreases were shown to be } \\
\text { equivalent across frequencies } \\
(p=0.00002) \\
\text { - Mean leg pain NRS scores decreased } \\
\text { from } 5.5 \pm 0.4 \text { (baseline) to } 2.6 \pm 0.4 \\
(1 \mathrm{kHz}), 2.7 \pm 0.4(4 \mathrm{kHz}), 2.7 \pm 0.4 \\
(7 \mathrm{kHz}) \text { and } 2.9 \pm 0.4(10 \mathrm{kHz}) \text {. Again, } \\
\text { these results were equivalent across } \\
\text { frequencies }(p=0.003)\end{array}$ & [59] \\
\hline
\end{tabular}

months, $50 \%$ (7 out of 14) of implanted patients showed more than $30 \%$ reduction in headache days. Among the entire cohort, the overall reduction in headache days was 6.9 per month and among responders it was 12.9. This study provided a possible treatment option for this historically difficult patient population [54].

Al-Kaisy et al. were the first to publish an investigation of the efficacy of HF10 in patients with no prior history of spine surgery in 2017 [55]. This pilot study involved 21 subjects with chronic axial low-back pain who failed conventional medical management (CMM) and were not surgical candidates. All but one of the patients $(20 / 21)$ had a successful HF10 trial and proceeded with implantation of the Nevro Senza system. Since this was a proof- 
of-concept study, there was no single primary end point. However, back pain scores were significantly reduced at each postimplant follow-up ( $\mathrm{p}<0.0001)$, with reductions in average VAS scores of 59.9 and $72.6 \%$ at 6 and 12 months, respectively. Functional improvement as measured by ODI scores was also significantly lower at all time points, with a reduction of $47.6 \%$ compared with baseline at the 12 -month follow-up.

The authors then published their results from the 36-month postimplant visit with the same cohort in 2018 [56]. Three subjects $(17 / 20)$ were lost to follow-up after the preliminary study. Reductions in mean VAS scores for axial back pain were sustained at 36 months (baseline VAS $79 \pm 12$ to $10 \pm 12 \mathrm{~mm}, \mathrm{p}<0.0001$ ), with $80 \%$ of the subjects endorsing greater than $50 \%$ reduction. Although this study targeted patients with a predominantly back pain component, significant VAS reductions were also seen in those with leg pain (baseline VAS $33 \pm 21$ to $9 \pm 13 \mathrm{~mm}$ ) at 36 months. Similarly, ODI scores had sustained reductions at 36 months (baseline $53 \pm 13$ to $19.8 \pm 13, \mathrm{p}<0.0001)$ and subjects had significant improvements in health-related quality of life and mental health metrics. Opioid use also declined among subjects, with $88 \%$ being opioid free at 36 months compared with $10 \%$ at baseline. These results exhibit similar trends to the SENZA-RCT and SENZA-EU studies and demonstrate the potential utility of HF10 for 'virgin back' patients with refractory axial back pain who are poor surgical candidates [2,5].

In 2019, Amirdelfan et al. published results from a prospective, multicenter study that demonstrated the efficacy of HF10 therapy for the treatment of chronic neck and/or upper limb pain [57]. Pain etiology was heterogeneous for the patient population, with $66.7 \%$ having previously had cervical spine surgery. With a trial success rate of $89.1 \%$, 45 patients were implanted. Eighty-six percent (39/45) of the patients achieved the primary end point, which was $\geq 50 \%$ relief from baseline at 3 months follow-up. Subjects showed a significant decrease $(p<0.001)$ in mean VAS scores for both neck (baseline $7.6 \pm 0.2$ to $2.4+0.4 \mathrm{~cm}$ ) and arm pain (baseline $7.1 \pm 0.3$ to $1.8 \pm 0.5 \mathrm{~cm}$ ) at 3 months, which were sustained at the 12 -month end point. Responder rates (defined as $\geq 50 \%$ relief) at 12 months for neck and arm pain (89.2\% for neck pain, 95\% for arm pain) were also higher compared with T-SCS and dorsal nerve root stimulation (both 67\%) reported from previous studies [60]. Furthermore, the rate of neck and arm pain remitters (defined as VAS scores $\leq 2.5 \mathrm{~cm}$ ) were 78.4 and $80 \%$, respectively, at 12 months. Additional improvements in metrics for disability/quality of life, overall satisfaction and sleep were also reported. Though opioid reduction was not actively encouraged for this study, $30 \%$ of the subjects decreased or eliminated opioid use at 12 months. It should also be noted that only $1 / 45$ patients $(2.2 \%)$ underwent device explantation, which is often an issue for patients using traditional cervical SCS devices due to positional variations in paresthesias.

As previously mentioned, the SENZA-RCT and SENZA-EU studies were critical for demonstrating the efficacy of HF10 for treating chronic low back and leg pain [2,5]. Al-Kaisy et al. published results from a post hoc analysis in 2019 on opioid usage for 137 patients taken from both SENZA studies [58]. While opioid reduction was not a primary end point for either study, mean opioid use among all patients declined by $41 \%$ at the 12 -month follow-up (baseline $104.2 \pm 9.0$ to $61.4 \pm 6.9 \mathrm{MME}, \mathrm{p}<0.001$ ), with the percentage of subjects who eliminated opioids also increasing $(1.6-27 \%, \mathrm{p}<0.0001)$. When looking at each study separately, SENZA-EU subjects had a greater reduction (92.3 \pm 15.6 to $28.1 \pm 6.0 \mathrm{MME})$ compared with SENZA-RCT (112.7 \pm 10.5 to $87.9 \pm 10.3 \mathrm{MME})$. Subgroup analysis of patients on high-dose opioids (>90 MME) prior to HF10 therapy demonstrated a $45.9 \%$ reduction at 12 months $(196.8 \pm 14.2$ to $106.5 \pm 14.1$ MME, $\mathrm{p}<0.0001)$. Corresponding reductions in pain scores are discussed elsewhere in this paper [2,5]. Reductions in opioid use with concomitant improvements in pain scores across both SENZA studies show the utility of HF10 therapy as a superior treatment modality and an important adjunct for reducing opioid use.

While HF10 stimulation has been shown in multiple studies to provide superior pain relief compared with traditional frequencies, other studies have found that kilohertz frequency stimulation at pulse frequencies other than $10 \mathrm{kHz}$ can be equally effective [59]. A total of 34 patients underwent a paresthesia-based SCS trial and 33 patients were found to have a greater than $50 \%$ decrease in their pain. These patients were implanted with a permanent system. Next, these 33 patients underwent a 'sweet spot' search with $10 \mathrm{kHz}$ stimulation to find the optimal stimulation location. Twenty-one patients found at least $30 \%$ pain relief during this process. Next, the 21 patients had a double-blind rate randomization phase where each patient experienced 1, 4, 7 and $10 \mathrm{kHz}$ stimulation in randomized order, all at the 'sweet spot' location. A washout phase of a few days to 1 week was allowed between the different frequency settings. Each frequency was experienced for 4 weeks, and pulse width and amplitude were adjusted throughout the first 3 weeks to allow optimal pain relief. Twenty patients completed this portion of the study. The mean back pain NRS scores decreased from $6.8 \pm 0.3$ (baseline, mean \pm standard error of the mean) to $3.2 \pm 0.3(1 \mathrm{kHz}), 3.5 \pm 0.3(4 \mathrm{kHz}), 3.2 \pm 0.3(7 \mathrm{kHz})$ and $3.3 \pm 0.4(10 \mathrm{kHz})$. These decreases 
were shown to be equivalent $(\mathrm{p}=0.00002)$. The mean leg pain NRS scores decreased from $5.5 \pm 0.4$ (baseline) to $2.6 \pm 0.4(1 \mathrm{kHz}), 2.7 \pm 0.4(4 \mathrm{kHz}), 2.7 \pm 0.4(7 \mathrm{kHz})$ and $2.9 \pm 0.4(10 \mathrm{kHz})$. Again, these results were equivalent across frequencies $(\mathrm{p}=0.003)$.

\section{Real-world evidence}

Real-world data continue to uphold the results presented in previously published studies. In 2018, DiBenedetto et al. retrospectively compared 64 patients who received CMM and 32 patients who received SCS plus CMM in the treatment of chronic low-back pain, with or without radicular lower-extremity pain, to determine any difference in analgesia or perceived disability with the addition of HF10 at a single community-based interdisciplinary pain center over a 3-year period [61]. CMM included traditional interventional procedures, such as epidural steroid injections, facet joint injections, radiofrequency ablations and major joint injections. The patients who underwent SCS + CMM were followed for 12 months prior to SCS implantation as well as 12 -month postimplantation. The CMM group was likewise followed for 24 months. Office visit volumes were recorded to determine the costs of healthcare utilization. The use of SCS + CMM was associated with improvements in low-back and lower-extremity pain as well as perceived disability. The addition of SCS allowed for statistically significant reductions in opioid use compared with patients undergoing CMM only. The authors postulated that this could decrease healthcare costs due to reductions in both medication utilization and number of interventional procedures. Both groups showed a decrease in modified Roland-Morris Disability Questionnaire scores, indicating a reduction in disability. These data highlight the addition of HF10 as a means of reducing opioid use, perceived disability and healthcare utilization costs.

One year later, Stauss et al. reviewed 1660 patients with chronic axial and/or limb pain who underwent HF10 implantation over a 4-year period across multiple international centers to assess real-world outcomes [4]. They assessed responsiveness to therapy, preferred programming of the SCS device, overall change in medication usage, change in function, change in sleep, change in quality-of-life, satisfaction of therapy, device recharge experience, frequency of therapy adjustments and device usage while sleeping and driving. Of the patients treated with HF10, more than $70 \%$ experienced at least $50 \%$ pain relief 12 months after implantation $(\mathrm{n}=1131)$. They noted that additional HF10 optimization tools were utilized in $56.7 \%$ of patients; this included multiarea pain sequencing, bipole interlacing programs and pulse dosing. At their last visit, $72.3 \%$ of patients reported functional improvement and $68.0 \%$ reported improved sleep. Improvement in quality of life was reported in $90.3 \%$ of all patients. A majority of patients reported convenient recharging of the device and only $2.2 \%$ of the patients reported adjusting their therapy more often than two to three times per week. A large majority of patients reported sleeping $(98.7 \%)$ and driving $(98.2 \%)$ with their devices on. A decrease in medication use was reported in $32.1 \%$ of patients. Three hundred and eighty-two patients had previously failed T-SCS and of the 266 for whom there were data, $74.1 \%$ responded to therapy, 32\% reported decreased medication use, $82.5 \%$ reported improved function and $70.0 \%$ reported improved sleep. The overall rate of explantation was 3.7\%, due to both loss of efficacy $(1.2 \%)$ and infection (1.7\%). These data are in line with previously published prospective study data [62,63].

\section{Safety \& tolerability}

The studies reviewed demonstrate safety profiles similar to well-accepted T-SCS safety profiles. In 2013, Van Buyten et al. reported that IPG site pain and lead migrations were noted to be the most common AEs [53]. Al-Kaisy et al. reported that these were the most common AEs and that this was in line with T-SCS. They reported no AEs directly related to stimulation effects [5]. Kapural $e t$ al. reported no stimulation-related neurological deficits. The authors did report comparatively low rates of lead migration and overall low incidence of study-related AEs [2]. They then extended these data to 24-month postimplantation and again demonstrated a favorable safety profile [3]. Arcioni et al. showed markedly less numbers of patients requiring additional surgery $(24 \%)$ than a previous study utilizing occipital nerve stimulation for chronic migraine (41\%) [54,64]. They reported few lead migrations $(n=2)$, infections $(\mathrm{n}=2)$ and minimal IPG site discomfort $(\mathrm{n}=1)$ as well. Al-Kaisy et al. have reported no serious AEs across several studies with the most common complications being pain at the IPG site or lead migration [55,56]. Amirdelfan et al. reported an improvement in neurological function in $4.4 \%$ of his patients and reported no stimulation-related neurological deficits. The authors reported two serious AEs: one extradural hematoma and one infection [57]. In real-world data, Stauss et al. reported that $3.7 \%$ of the patients had their devices explanted due to infection (1.7\%), loss of efficacy $(1.2 \%)$ and other reasons $(0.8 \%)$ in the 12 months following implantation, respectively [4]. None of the studies reviewed highlighted any AEs that were outside of the accepted values consistent with T-SCS. 


\section{Conclusion}

Since its seminal publication in 2015, HF10 has seen tremendous growth within the field of neuromodulation. This has been fueled by its commitment to quality research that seeks to demonstrate the efficacy and safety of HF10 in the treatment of conditions traditionally amenable to SCS, to determine the mechanism of action of their unique stimulation modality, and to expand the therapeutic indications of DC SCS. Additionally, real-world evidence continues to validate the expected patient outcomes. The Omnia IPG is the latest iteration of the Nevro Corp. Its offerings include programming frequencies from 2 to $10,000 \mathrm{~Hz}$ with the versatility to utilize multiple mechanisms of action, including traditional DC stimulation, paired waveforms and the direct neural inhibition that is only possible with HF10. This provides practitioners with the largest array of possible therapeutic options both in the initial and maintenance treatment of chronic pain conditions.

\section{Financial \& competing interests disclosure}

The authors have no relevant affiliations or financial involvement with any organization or entity with a financial interest in or financial conflict with the subject matter or materials discussed in the manuscript. This includes employment, consultancies, honoraria, stock ownership or options, expert testimony, grants or patents received or pending, or royalties.

No writing assistance was utilized in the production of this manuscript.

\section{References}

Papers of special note have been highlighted as: $\bullet$ of interest; $\bullet \bullet$ of considerable interest

1. Shealy CN, Mortimer JT, Reswick JB. Electrical inhibition of pain by stimulation of the dorsal columns: preliminary clinical report. Anesth. Analg. 46(4), 489-491 (1967).

2. Kapural L, Yu C, Doust MW et al. Novel 10-kHz high-frequency therapy (HF10 therapy) is superior to traditional low-frequency spinal cord stimulation for the treatment of chronic back and leg pain: the SENZA-RCT randomized controlled trial. Anesthesiology 123(4), 851-860 (2015).

-. Randomized controlled trial that led to the US FDA approval for the Senza system.

3. Kapural L, Yu C, Doust MW et al. Comparison of 10-kHz high-frequency and traditional low-frequency spinal cord stimulation for the treatment of chronic back and leg pain: 24-month results from a multicenter, randomized, controlled pivotal trial. Neurosurgery 79(5), 667-677 (2016).

- 24 months data from the original SENZA study that showed continued pain relief.

4. Stauss T, El Majdoub F, Sayed D et al. A multicenter real-world review of $10 \mathrm{kHz}$ SCS outcomes for treatment of chronic trunk and/or limb pain. Ann. Clin. Transl. Neurol. 6(3), 496-507 (2019).

- Large patient cohort showing real-world outcomes from the Senza system.

5. Al-Kaisy A, Van Buyten J-P, Smet I et al. Sustained effectiveness of $10 \mathrm{kHz}$ high-frequency spinal cord stimulation for patients with chronic, low back pain: 24-month results of a prospective multicenter study. Pain Medicine. 15(3), 347-354 (2014).

-. European randomized controlled trial data showing pain relief at 2 years.

6. U.S. Food \& Drug Administration. Premarket Approval (PMA): Nevro Senza spinal cord stimulation (SCS) system. https://www.accessdata.fda.gov/scripts/cdrh/cfdocs/cfpma/pma.cfm?id=P130022

7. Compton AK, Shah B, Hayek SM. Spinal cord stimulation: a review. Curr. Pain Headache Rep. 16, 35-42 (2012).

8. Melzack R, Wall PD. Pain mechanisms: a new theory. Science 150, 971-979 (1965).

9. Guan Y, Bradley K, Parker JL et al. Spinal cord stimulation: mechanisms of action. In: Neuromodulation: Comprehensive Textbook of Principles, Technologies, and Therapies. Krames E, Peckham PH, Rezai AR (Eds). Academic Press, San Diego, CA, 161-178 (2018).

10. Linderoth B, Meyerson BA. Spinal cord stimulation: exploration of the physiological basis of a widely used therapy. Anesthesiology 113 , 1265-1267 (2010).

11. Guan Y, Wacnik PW, Yang F et al. Spinal cord stimulation-induced analgesia: electrical stimulation of dorsal column and dorsal roots attenuates dorsal horn neuronal excitability in neuropathic rats. Anesthesiology 113, 1392-1405 (2010).

12. Foreman RD, Linderoth B. Neural mechanisms of spinal cord stimulation. Int. Rev. Neurobiol. 107, 87-119 (2012).

13. Meyerson BA, Linderoth B. Mode of action of spinal cord stimulation in neuropathic pain. J. Pain Symptom Manag. 31, S6-S12 (2006).

14. Falowski S, Sharan A. A review on spinal cord stimulation. J. Neurosurg. Sci. 56, 287-298 (2012).

15. Yakhnitsa V, Linderoth B, Meyerson BA. Spinal cord stimulation attenuates dorsal horn neuronal hyperexcitability in a rat model of mononeuropathy. Pain 79, 223-233 (1999).

16. Yang F, Xu Q, Cheong YK et al. Comparison of intensity-dependent inhibition of spinal widedynamic range neurons by dorsal column and peripheral nerve stimulation in a rat model of neuropathic pain. Eur. J. Pain 18, 978-988 (2014). 
17. Shechter R, Yang F, Xu Q et al. Conventional and kilohertz-frequency spinal cord stimulation produces intensity- and frequency-dependent inhibition of mechanical hypersensitivity in a rat model of neuropathic pain. Anesthesiology 119, 422-432 (2013).

18. Guan Y. Spinal cord stimulation: neurophysiological and neurochemical mechanisms of action. Curr. Pain Headache Rep. 16, 217-225 (2012).

19. Wallin J, Fiska A, Tjolsen A et al. Spinal cord stimulation inhibits long-term potentiation of spinal wide dynamic range neurons. Brain Res. 973, 39-43 (2003).

20. Narikawa $\mathrm{K}$, Furue $\mathrm{H}$, Kumamoto $\mathrm{E}$ et al. In vivo patch-clamp analysis of IPSCs evoked in rat substantia gelatinosa neurons by cutaneous mechanical stimulation. J. Neurophysiol. 84, 2171-2174 (2000).

21. Shimoji K, Shimizu H, Maruyama Y et al. Dorsal column stimulation in man: facilitation of primary afferent depolarization. Anesth. Analg. 61, 410-413 (1982).

22. Schoffnegger D, Heinke B, Sommer C et al. Physiological properties of spinal lamina II GABAergic neurons in mice following peripheral nerve injury. J. Physiol. 577, 869-878 (2006).

23. Daniele CA, MacDermott AB. Low-threshold primary afferent drive onto GABAergic interneurons in the superficial dorsal horn of the mouse. J. Neurosci. 29, 686-695 (2009).

24. Rees H, Roberts MH. Activation of cells in the anterior pretectal nucleus by dorsal column stimulation in the rat. J. Physiol. 417, 361-373 (1989).

25. Saade NE, Barchini J, Tchachaghian S et al. The role of the dorsolateral funiculi in the pain relieving effect of spinal cord stimulation: a study in a rat model of neuropathic pain. Exp. Brain Res. 233, 1041-1052 (2015).

26. Barchini J, Tchachaghian S, Shamaa F et al. Spinal segmental and supraspinal mechanisms underlying the pain-relieving effects of spinal cord stimulation: an experimental study in a rat model of neuropathy. Neuroscience 215, 196-208 (2012).

27. Song Z, Ansah OB, Meyerson BA et al. The rostroventromedial medulla is engaged in the effects of spinal cord stimulation in a rodent model of neuropathic pain. Neuroscience 247, 134-144 (2013).

28. Baba H, Yoshimura M, Nishi S et al. Synaptic responses of substantia gelatinosa neurones to dorsal column stimulation in rat spinal cord in vitro. J. Physiol. 478(1), 87-99 (1994).

29. Cui JG, O'Connor WT, Ungerstedt U et al. Spinal cord stimulation attenuates augmented dorsal horn release of excitatory amino acids in mononeuropathy via a GABAergic mechanism. Pain 73, 87-95 (1997).

30. Stiller CO, Cui JG, O'Connor WT et al. Release of gamma-aminobutyric acid in the dorsal horn and suppression of tactile allodynia by spinal cord stimulation in mononeuropathic rats. Neurosurgery 39, 367-374 (1996).

31. Song Z, Ultenius C, Meyerson BA et al. Pain relief by spinal cord stimulation involves serotonergic mechanisms: an experimental study in a rat model of mononeuropathy. Pain 147, 241-248 (2009).

32. Song Z, Meyerson BA, Linderoth B. Spinal 5-HT receptors that contribute to the pain-relieving effects of spinal cord stimulation in a rat model of neuropathy. Pain 152, 1666-1673 (2011).

33. Wang YY, Wu SX, Liu XY et al. Effects of c-fos antisense oligodeoxynucleotide on 5-HT-induced upregulation of preprodynorphin, preproenkephalin, and glutamic acid decarboxylase mRNA expression in cultured rat spinal dorsal horn neurons. Biochem. Biophys. Res. Commun. 309, 631-636 (2003).

34. Levin BE, Hubschmann OR. Dorsal column stimulation: effect on human cerebrospinal fluid and plasma catecholamines. Neurology 30 , 65-71 (1980).

35. Song Z, Meyerson BA, Linderoth B. Muscarinic receptor activation potentiates the effect of spinal cord stimulation on pain-related behavior in rats with mononeuropathy. Neurosci. Lett. 436, 7-12 (2008).

36. Schechtmann G, Song Z, Ultenius $\mathrm{C}$ et al. Cholinergic mechanisms involved in the pain relieving effect of spinal cord stimulation in a model of neuropathy. Pain 139, 136-145 (2008).

37. Lempka SF, McIntyre CC, Kilgore KL, Machado AG. Computational analysis of kilohertz frequency spinal cord stimulation for chronic pain management. Pain Med. 122, 1362-1376 (2015).

38. Song Z, Viisanen H, Meyerson BA et al. Efficacy of kilohertz-frequency and conventional spinal cord stimulation in rat models of different pain conditions. Neuromodulation 17(3), 226-235 (2014).

39. Crosby ND, Janik JJ, Grill WM. Modulation of activity and conduction in single dorsal column axons by kilohertz-frequency spinal cord stimulation. J. Neurophysiol. 117(1), 136-147 (2017).

40. Lee K, Lee D, Kagan ZB et al. Different neuronal cell types in superficial dorsal horn of rats are differentially affected by high frequency $\mathrm{kHz}$ spinal cord stimulation. Presented at the North American Neuromodulation Society 2018 Annual Meeting. Las Vegas, NV, USA, 11-14 January 2018.

41. Cuellar JM, Alataris K, Walker A et al. Effect of high-frequency alternating current on spinal afferent nociceptive transmission. Neuromodulation 16, 318-327 (2013).

42. Arle JE, Mei L, Carlson KW, Shils JL. High-frequency stimulation of dorsal column axons: potential underlying mechanisms of paresthesia-free neuropathic pain relief. Neuromodulation 19(4), 385-397 (2016). 
43. McMahon S, Smith M. Effects of $10 \mathrm{KHz}$ spinal stimulation (I): inhibition of output neurons of the dorsal horn. Presented at Neuromodulation - the Science Meeting in 2016. San Francisco, CA, USA May 25-29, 2016.

44. Kasapovic A, Rommelspacher Y, Gathen M et al. High-frequency spinal cord stimulation for the treatment of chronic low back and leg pain: implantation technique of percutaneous leads and implantable pulse generator. Arthrosc. Tech. 8(10), e1125-e1129 (2019).

45. Russo M, Van Buyten J-P. 10-kHz high-frequency SCS therapy: a clinical summary. Pain Med. 16(5), 934-942 (2015).

46. Nevro. Physician implant manual: Senza and Senza II. https://www.accessdata.fda.gov/cdrh_docs/pdf13/P130022d.pdf

47. Ghosh PE, Simopolous TT. A review of the Senza system: a novel, high frequency $10 \mathrm{kHz}$ (HF10), paresthesia free spinal cord stimulator. Pain Manag. 9(3), 225-231 (2019).

48. North RB, Kidd DH, Zahurak M et al. Spinal cord stimulation for chronic, intractable pain: experience over two decades. Neurosurgery 32, 384-394 (1993).

49. Kumar K, Hunter G, Demeria D. Spinal cord stimulation in treatment of chronic benign pain: challenges in treatment planning and present status, a 22-year experience. Neurosurgery 58, 481-496 (2006).

50. Hayek SM, Veizi E, Hanes M. Treatment-limiting complications of percutaneous spinal cord stimulator implants: a review of eight years of experience from an academic center database. Neuromodulation 18, 603-608 (2015).

51. Reddy RD, Moheimani R, Yu GG et al. A review of clinical data on salvage therapy in spinal cord stimulation. Neuromodulation (2019) (Epub ahead of print).

52. Russo M, Thomas F, Prickett J et al. Improved versatility and frequency pairing capabilities with $10 \mathrm{kHz}$ spinal cord stimulation for the treatment of chronic pain. Poster presented at the North American Neuromodulation Society's 2020 Annual Meeting. Las Vegas, NV, USA January 23-26, 2020.

53. Van Buyten J-P, Al-Kaisy A, Smet I et al. High-frequency spinal cord stimulation for the treatment of chronic back pain patients: results of a prospective multicenter european clinical study. Neuromodulation 16, 59-66 (2013).

54. Arcioni R, Palmisani S, Mercieri M et al. Cervical $10 \mathrm{kHz}$ spinal cord stimulation in the management of chronic, medically refractory migraine: a prospective, open-label, exploratory study. Eur. J. Pain 20, 70-78 (2016).

55. Al-Kaisy A, Palmisani S, Smith TE et al. $10 \mathrm{kHz}$ high-frequency spinal cord stimulation for chronic axial low back pain in patients with no history of spinal surgery: a preliminary, prospective, open label and proof-of-concept study. Neuromodulation 20, 63-70 (2017).

56. Al-Kaisy A, Palmisani S, Smith TE et al. Long-term improvements in chronic axial low back pain patients without previous spinal surgery: a cohort analysis of 10-kHz high-frequency spinal cord stimulation over 36 months. Pain Med. 19, 1219-1226 (2018).

57. Amirdelfan K, Vallejo R, Benyamin R et al. High-frequency spinal cord stimulation at $10 \mathrm{kHz}$ for the treatment of combined neck and arm pain: results from a prospective multicenter study. Neurosurgery (87(2), 176-185 (2020).

-. Study investigating HF10 for neck and arm pain.

58. Al-Kaisy A, Van Buyten J-P, Carganillo R et al. $10 \mathrm{kHz}$ SCS therapy for chronic pain, effects on opioid usage: post hoc analysis of data from two prospective studies. Sci. Rep. 9(1), 11441 (2019).

- Post hoc analysis of two large randomized controlled trials assessing opioid usage.

59. Thomson SJ, Tavakkolizadeh M, Love-Jones $S$ et al. Effects of rate on analgesia in kilohertz frequency spinal cord stimulation: results of the PROCO randomized controlled trial. Neuromodulation 21, 67-76 (2018).

60. Levine AB, Parrent AG, MacDougall KW. Cervical spinal cord and dorsal nerve root stimulation for neuropathic upper limb pain. Can. J. Neurol. Sci. 44(1), 83-89 (2017).

61. DiBenedetto DJ, Wawrzyniak KM, Schatman M et al. $10 \mathrm{kHz}$ spinal cord stimulation: a retrospective analysis of real-world data from a community-based, interdisciplinary pain facility. J. Pain Res. 11, 2929-2941 (2018).

62. Hayek SM, Veizi E, Hanes M. Treatment-limiting complications of percutaneous spinal cord stimulator implants: a review of 8 years of experience from an academic center database. Neuromodulation 18, 603-608 (2015).

63. Provenzano DA, Deer T, Luginbuhl Phelps A et al. An international survey to understand infection control practices for spinal cord stimulation. Neuromodulation 19(1), 71-84 (2016).

64. Dodick DW, Silberstein SD, Reed KL et al. Safety and efficacy of peripheral nerve stimulation of the occipital nerves for the management of chronic migraine: long-term results from a randomized, multicenter, double-blinded, controlled study. Cephalalgia 35(4), 344-358 (2014). 